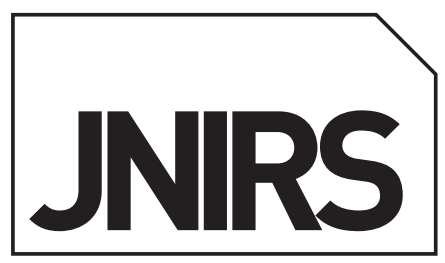

\title{
Characterisation and classification of Italian virgin olive oils by near- and mid-infrared spectroscopy
}

\author{
Nicolett Sinelli, ${ }^{a *}$ Ernestina Casiraghi, ${ }^{a}$ Debora Tura ${ }^{\mathrm{b}}$ and Gerard Downey ${ }^{\mathrm{c}}$ \\ aDepartment of Food Science and Technologies, University of Milan, Via Celoria 2, 20133 Milan, Italy. E-mail: nicoletta.sinelli@unimi.it, \\ ernestina.casiraghi@unimi.it \\ bDepartment of Crop Production, University of Milan, Via Celoria 2, 20133 Milan, Italy. E-mail: debora.tura@unumi.it \\ 'Teagasc, Ashtown Food Research Centre, Ashtown, Dublin 15, Ireland. E-mail: gerard.downey@teagasc.ie
}

\begin{abstract}
Virgin olive oil quality is the result of complex interactions between olive variety, environment and cultivar practice. Evaluation of its quality is based on chemical and sensory analyses (ECC Regulation) that are time-consuming, expensive and destructive of the sample. Spectroscopic techniques present significant advantages in terms of speed and cost of analysis per sample. Italian extra virgin olive oils from Lombardy, Tuscany and Calabria were analysed by conventional analytical and spectroscopic methods. The sample set was composed of 60 single-cultivar (Casaliva, Leccino and Frantoio) extra virgin olive oils (monovarietal extra virgin olive oils) and 59 extra virgin olive oils produced from a mixture of cultivars from each geographical area (industrial extra virgin olive oils). Free acid content, peroxide value and spectrophotometric indices $\left(K_{232}, K_{270}\right.$ and $\left.\Delta K\right)$ were measured. Olive oils were also analysed by near infrared (NIR) and mid-infrared (MIR) spectroscopy in transmission and attenuated total reflectance, respectively, to classify oils on the basis of their geographical origin. Principal component analysis was applied both to chemical and spectral data as an exploratory technique. Classification methods studied were linear discriminant analysis, partial least squares discriminant analysis and soft independent modelling of class analogy (SIMCA). Both FT-NIR and FT-IR allowed sample classification of oils on the basis of geographical origin. NIR spectroscopy was able to classify better the industrial extra virgin olive oils producing a correct classification of about $90 \%$ of the samples, while the MIR technique was able to classify both monovarietal and industrial olive oils, allowing a higher correct classification of samples (>95\%). SIMCA applied to MIR spectra classified about $70 \%$ of samples correctly on the basis of geographical origin.
\end{abstract}

Keywords: NIR spectroscopy, MIR spectroscopy, extra virgin olive oils, geographical origin, classification techniques, chemometric analysis

\section{Introduction}

Extra virgin olive oil is widely used in the Mediterranean diet due to its health value and unique flavour (fatty acids, phenols, tocopherols, pigments, volatile compounds etc.). ${ }^{1}$ With Council Regulation (EEC) no. 2081/1992, ${ }^{2}$ the European Community established the Protected Designation of Origin (PDO) and Protected Geographical Indication (PGI) to improve and protect food quality. The Italian Department of Agriculture approved several regulations concerning Italian PDO oils to enhance the Italian extra virgin olive oil. Moreover, the EC approved many regulations to defend consumers from food adulteration and to define oil quality and avoid its adulteration. One of the most recent is the Commission Regulation (EC) no. 1989/2003, ${ }^{3}$ setting oil characteristics and analytical methods for their assessment. Different techniques and new methods are developing with a view to checking oil quality in all its aspects, from detecting adulterations to confirming geographical origin.

Near infrared spectroscopy has been applied with good results to identify adulteration of extra virgin olive oils with 
other vegetable oils. Some authors ${ }^{4,5}$ demonstrated that it is possible to discriminate between authentic extra virgin olive oils from olive oils adulterated at different levels with sunflower oil. Also Wesley et al. ${ }^{6,7}$ investigated olive oil samples adulterated with different vegetable oils (sunflower oil, rapeseed oil, soybean oil and corn oill designing a quality control system to predict the level of adulteration. Confirming the authenticity of extra virgin olive oils was also investigated by FT-IR attenuated total reflectance (ATR) spectroscopy. This technique was used to detect the adulteration of extra virgin olive oil with hazelnut oil ${ }^{8,9}$ and to identify olive oil samples adulterated with different levels of sunflower oil. ${ }^{10}$

NIR, in association with statistical procedures and in combination with traditional analytical methods, is used also for oil and fat classification. Hourant et al. ${ }^{11}$ and Yang et al. ${ }^{12}$ classified the samples according to their vegetable and animal origin, determining rapidly in a simple way the authenticity of edible oils and fats. Nine varieties of vegetable oils were also differentiated by Sato ${ }^{13}$ on the basis of their NIR spectra, validating the classification achieved by the use of the fatty acid composition of the oils. NIR and MIR technologies were also used to evaluate the quality of oil obtained by olives stored in controlled atmosphere ${ }^{14}$ and to verify the freshness of extra virgin olive oils stored at different conditions. ${ }^{15}$

Many analytical methodologies have been used to investigate the geographical origin of extra virgin olive oil. These new analytical techniques need to be faster and cheaper than the traditional methods. The results obtained by Downey et al., ${ }^{16}$ Bertran et al., ${ }^{17}$ Carazzolo et al. ${ }^{18}$ and Galtier et al. ${ }^{19}$ suggest that NIR spectroscopy has the potential to separate

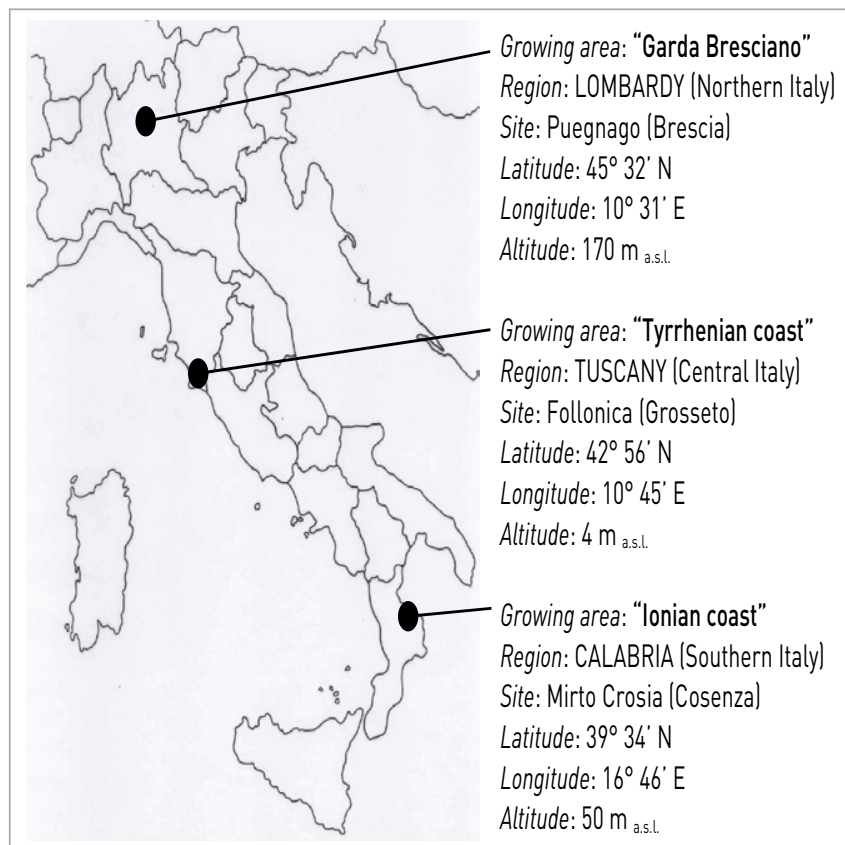

Figure 1. A map of the Italian region where the olives were collected. virgin olive oils coming from adjacent geographic regions with a high degree of accuracy and to discriminate olive oils bearing different denominations of origin. Other authors have used an electronic nose to identify geographical origin; this method has been successfully used for discriminating the geographic origin within small areas, such as Iberian and Italian regions. ${ }^{20,21}$ A new classification method (CAIMAN) applied on chemical and electronic nose and tongue data has allowed the geographical classification of olive oil samples with different PDO labels and belonging to different production areas. ${ }^{22}$ In the end, data collected by nuclear magnetic resonance (NMR) showed the existence of reliable parameters able to group olive oils according to the location of olive oil production..$^{23}$

The aim of this work is the characterisation and classification of Italian virgin olive oils by IR spectroscopy, a quick, easy technique not requiring sample preparation or the use of chemical reagents. Discrimination is sought between extra virgin olive oils (monovarietal and industrial extra virgin olive oil samples) from adjacent Italian regions: Lombardy in northern Italy, Tuscany in the central region and Calabria in the south.

\section{Materials and methods Oil sampling}

Olive oil production was carried out in three different sites representative of Italian olive growing regions, i.e. northern, central and southern Italy (Figure 1). In particular, Puegnago is representative of the "Garda Bresciano" area (western shore of Lake Garda) in the Lombardy region (northern Italy); Follonica, in the "Tyrrhenian coast" area in Tuscany region (central Italy); and Mirto in the "Ionian coast" area in the Calabria region (southern Italy).

A total of 119 Italian extra virgin olive oils collected in 2005 were analysed. This sample set comprised 60 monovarietal extra virgin olive oils obtained by the single-cultivars Casaliva, Leccino and Frantoio (20 from Lombardy, 19 from Tuscany and 21 from Calabrial and 59 industrial extra virgin olive oils (20 from Lombardy, 20 from Tuscany and 19 from Calabria) obtained from a mixture of cultivars characteristic of each geographical area.

The monovarietal extra virgin olive oil samples were obtained from $6-10 \mathrm{~kg}$ of olives using a standard continuous procedure in a mini oil mill (Toscana Enologica Mori, mod. Mini 50 modified, Tavarnelle Val Di Pesa) within three days of picking. The olives, collected at commercial maturity according to a maturity index suggested by Uceda, ${ }^{24}$ were crushed with a hammer mill and the crushed olive pasta was then submitted to a malaxation $\left(20^{\circ} \mathrm{C}\right.$ for $\left.20 \mathrm{~min}\right)$ to allow the microscopic oil droplets to coalesce into larger globules. The oil was then centrifuged for $10 \mathrm{~min}$ at $3000 \mathrm{rpm}$. Industrial oil samples, produced from locally-grown olives, were collected from different oil companies in three regions; all oils were stored at $0-4^{\circ} \mathrm{C}$ until analysis. 


\section{Chemical analyses}

According to official methods of the European Regulation/ Commission Regulation EEC no. 2568/9125 several variables were measured: the free acidity, indicative of the acid content of the oil, expressed as oleic acid (\%); the peroxide value (PV), which is a measure of the amount of the hydroperoxides ( $m e q \mathrm{O}_{2} \mathrm{~kg}^{-1}$ ) due to oxidation; and the spectrophotometric indices, i.e. the UV absorbance at $232 \mathrm{~nm}$ and $270 \mathrm{~nm}\left(K_{232}\right.$. $K_{270}$ and $\Delta K$ ), a measure of double bond configuration. All the chemicals and solvents used were of analytical grade.

\section{NIR spectroscopy}

NIR spectral data were collected in transmission mode using vials of $8 \mathrm{~mm}$ path length with an FT-NIR spectrometer (MPA, Bruker Optics, Milan, Italy). The spectral data were collected over the range 12,500-4500 $\mathrm{cm}^{-1}$ (resolution $8 \mathrm{~cm}^{-1}$, scanner velocity: $10 \mathrm{KHz}$, background: 64 scans, sample: 64 scans) at room temperature. Instrument control and initial data processing were performed using OPUS software (v. 5.5, Bruker Optics, Milan, Italy). Spectral data were pre-treated using a second derivative calculation (Savitzky-Golay method, number of smoothing points $=10$ ) to reduce baseline shift.

\section{MIR spectroscopy}

ATR FT-IR experiments were performed on a spectrometer (Vertex 70, Bruker Optics, Milan, Italy) equipped with a deuterated triglycine sulphate (DTGS) detector. For both background and sample, $16 \mathrm{~cm}^{-1}$ asymmetric interferograms with a spatial resolution of $4 \mathrm{~cm}^{-1}$ were co-added and Fourier transformed. The oil samples were positioned on a horizontal germanium crystal ATR plate with 11 internal reflections. For each sample, spectral data were collected in the range $4000-700 \mathrm{~cm}^{-1}$ at room temperature $\left(20 \pm 0.5^{\circ} \mathrm{C}\right)$ and stored as $\log (1 / R)$ files. Opus software (v. 5.5, Bruker Optics, Milan, Italy) was used for spectral acquisition, instrument control and preliminary file manipulation. The spectra were compensated to eliminate disturbing $\mathrm{H}_{2} \mathrm{O}$ and/or $\mathrm{CO}_{2}$ bands in the ratio spectra.

\section{Data processing}

Principal component analysis (PCA) was performed as an explorative analysis on each data set (FT-NIR and FT-IR spectral in order to display the data structure and to reduce the dimensionality of the spectral data to a small number of components. ${ }^{26}$ PCA was performed using The Unscrambler software package (Version 9.6, Camo, Oslo, Norway).

To confirm the authenticity of olive oil on the basis of variety and geographical origin, classification methods were applied. In particular, for discriminant analysis, the Lombardy olive oils were ascribed to class 1, the Tuscany olive oils to class 2 and Calabria olive oils to class 3. Classification techniques investigated were linear discriminant analysis (LDA), partial least square discriminant analysis (PLS-DA) and soft independent modelling of class analogy (SIMCA).

Linear discriminant analysis (LDA) is a supervised classification technique in which the number of categories and the samples belonging to each category are previously defined. The criterion of LDA for selection of latent variables (LVs) maximises the differences between categories and minimises the variances within categories. The method produces a number of orthogonal linear discriminant functions, equal to the number of the categories minus one, that allow the samples to be classified into one or another category. ${ }^{27}$ LDA was carried out on the PCA sample scores of the significant components (PCs) using full cross-validation (leave one out method) by SPSS software (Version 14.0, SPSS, Chicago, USA).

PLS-DA is a variant of partial least square regression (PLS) in which each sample in the calibration set is assigned a dummy variable $(0,1)$ as a reference value. The classification of the olive oils according to geographical origin was on the basis of a 0.5 cut-off value for this dummy variable. For each class, olive oils samples were split into calibration and prediction sample sets, assigning samples to each set on the basis of their position in the class file, i.e. $50 \%$ of samples were used for calibration and the remainder for prediction. ${ }^{27}$ The PLS-DA regression used in this study was performed using the PLS Il model regression in The Unscrambler Version 9.6. Camo, Oslo, Norwayl.

SIMCA considers different classes individually modelled by a separate principal component analysis. The number of significant PCs is determined for each class and are obtained by training. The test set is used to test all class models. ${ }^{27}$ SIMCA models were developed using three classes (Lombardy, Tuscany and Calabria olive oils) using The Unscrambler (Version 9.6, Camo, Oslo, Norway). Class cut-off limits in SIMCA were set at the $5 \%$ level.

\section{Results and discussion}

Table 1 shows the minimum, maximum, mean and standard deviation of acid content, $P V, K_{232}$ and $K_{270}$ values of all monovarietal and industrial extra virgin oils from Lombardy, Tuscany and Calabria. Most of the oils were classed as "extra virgin" as their acid content, $P V, K_{232}, K_{270}$ and $\Delta K$ were within the limits of the Commission Regulation EC no. 1989/2003: ${ }^{3}$ acid content $\leqslant 0.8 \%, P V \leqslant 20 \mathrm{meq}_{2} \mathrm{~kg}^{-1}, K_{232} \leqslant 2.5, K_{270} \leqslant 0.22$ and $\Delta K \leqslant 0.01$. Only three monovarietal oil samples from Calabria had an acid value higher than the legal limit.

A preliminary examination of the NIR spectra was performed by PCA on second derivative spectra in the range $9000-4500 \mathrm{~cm}^{-1}$. The results of PCA of industrial extra virgin olive oils are shown in Figure 2. The scatter plot of scores on PC1 and PC2 (Figure 2a) (78\% of the total variance) was able to separate oils on the basis of geographical origin. In particular, Lombardy industrial extra virgin olive oils were distributed on positive PC1 values while olive oils belonging to Calabria and Tuscany region were located on the negative PC1 plane. Thus, a fairly good separation was possible on the basis of geographical origin even if the olive oil samples from Calabria and Tuscany were not well separated from each other (PC2 accounts for $27 \%$ of total variance). The corresponding loading plots were analysed in order to find 
Table 1. Chemical data of oil samples: minimum, maximum, mean and standard deviation.

\begin{tabular}{|c|c|c|c|c|c|c|c|}
\hline & & \multicolumn{3}{|c|}{ Monovarietal oils $(N=60)$} & \multicolumn{3}{|c|}{ Industrial oils ( $N=59)$} \\
\hline & & Lombardy & Tuscany & Calabria & Lombardy & Tuscany & Calabria \\
\hline & & $(n=20)$ & $(n=19)$ & $(n=21)$ & $(n=20)$ & $(n=20)$ & $(n=19)$ \\
\hline \multirow[t]{4}{*}{ Acid content (\%) } & Min & 0.11 & 0.12 & 0.18 & 0.11 & 0.14 & 0.11 \\
\hline & Max & 0.71 & 0.39 & 1.46 & 0.51 & 0.48 & 0.58 \\
\hline & Mean & 0.34 & 0.21 & 0.50 & 0.24 & 0.24 & 0.32 \\
\hline & $S D$ & 0.16 & 0.08 & 0.34 & 0.09 & 0.09 & 0.11 \\
\hline \multirow[t]{4}{*}{$P V\left(\right.$ meq $\left.\mathrm{O}_{2} \mathrm{~kg}_{-1}\right)$} & Min & 4.8 & 2.7 & 3.2 & 5.1 & 4.1 & 4.2 \\
\hline & Max & 9.9 & 5.9 & 11.6 & 13.0 & 8.8 & 16.2 \\
\hline & Mean & 6.5 & 3.7 & 7.0 & 7.4 & 6.2 & 8.2 \\
\hline & $S D$ & 1.4 & 0.9 & 2.4 & 1.8 & 1.2 & 2.5 \\
\hline \multirow[t]{4}{*}{$K_{232}$} & Min & 1.20 & 1.14 & 1.18 & 0.88 & 1.16 & 1.19 \\
\hline & Max & 1.43 & 1.47 & 1.47 & 1.30 & 1.51 & 1.46 \\
\hline & Mean & 1.30 & 1.35 & 1.34 & 1.10 & 1.31 & 1.36 \\
\hline & $S D$ & 0.06 & 0.09 & 0.08 & 0.12 & 0.07 & 0.08 \\
\hline \multirow[t]{4}{*}{$K_{270}$} & Min & 0.08 & 0.10 & 0.07 & 0.07 & 0.08 & 0.11 \\
\hline & Max & 0.15 & 0.18 & 0.15 & 0.15 & 0.15 & 0.15 \\
\hline & Mean & 0.10 & 0.13 & 0.10 & 0.10 & 0.11 & 0.13 \\
\hline & $S D$ & 0.02 & 0.02 & 0.02 & 0.02 & 0.02 & 0.01 \\
\hline \multirow[t]{4}{*}{$\Delta K$} & Min & 0.000 & 0.000 & 0.000 & 0.000 & 0.000 & 0.000 \\
\hline & Max & 0.003 & 0.002 & 0.002 & 0.002 & 0.004 & 0.003 \\
\hline & Mean & 0.001 & 0.001 & 0.001 & 0.001 & 0.002 & 0.002 \\
\hline & $S D$ & 0.001 & 0.001 & 0.001 & 0.001 & 0.001 & 0.001 \\
\hline
\end{tabular}

which variables influenced separation of the oils [Figure 2(b) and 2(c)]. As can be seen in the PC1 and PC2 loading plots, the major peaks arising from methyl, methylene and ethylene groups were identified as important wavenumbers for describing variation among oils. ${ }^{11-16}$ On PC1, the main wavenumbers were 5789, 5847, 5743 and $5693 \mathrm{~cm}^{-1}$ arising from the first overtone of $\mathrm{C}-\mathrm{H}$ stretching vibrations of methyl, methylene and ethylene groups. Some authors reported that oleic acid absorbs at $1725 \mathrm{~nm}\left(5797 \mathrm{~cm}^{-1}\right)$ and saturated and trans-unsaturated triglycerides absorb at $1725 \mathrm{~nm}$ and $1760 \mathrm{~nm}\left(5797 \mathrm{~cm}^{-1}\right.$ and $\left.5681 \mathrm{~cm}^{-1}\right)$. Small absorbances at $4678 \mathrm{~cm}^{-1}$ could be associated with the presence of cis double bonds, while absorbances at $5291-5230 \mathrm{~cm}^{-1}$ are due to the combination bands arising from $\mathrm{O}-\mathrm{H}$ stretching vibration of water

The variation in the above absorption bands could be related to compositional differences among oils groups; moreover, the role of water bands in discriminating oils of different geographical origins could arise from water traces caused by different production technologies.

PCA applied to the second derivative of monovarietal extra virgin olive oils was not as successful as those obtained with industrial extra virgin olive oils. In fact, the scatter plot 138\% of the total variance) showed only a partial separation between oils according to geographical origin (results not shown). This weak ability of NIR spectroscopy in discriminating monovarietal oil classes could be associated with the composition of samples in data set. In each region, monovarietal oils were comprised of the same three varieties (Casaliva, Leccino, Frantoio), while the industrial oils were obtained by a mixture of cultivars and in each region a cultivar characteristic of the geographical area was predominant.

For this reason, the classification techniques, LDA and PLS-DA analysis, were only applied to the second derivative spectra of industrial multivarietal oils in the frequency range $8900-4500 \mathrm{~cm}^{-1}$. Classification of Lombardy oils (class 1), Tuscany oils (class 2) and Calabria oils (class 3) was first attempted applying LDA to the scores of the first and second PCs. In cross-validation, Lombardy oils and Tuscany oils were $85 \%$ correctly classified while the samples belonging to class 3 were $89 \%$ correctly classified. In any case, an overall rate of $86 \%$ correct classification by cross-validation was achieved. The misclassified samples belonging to class 1 (Lombardy oils) were classified as belonging to class 2 (Tuscany oils) and vice versa, while the misclassified samples belonging to class 3 (Calabria oils) were classified as belonging to class 2 .

PLS-DA was applied to the same classes; the model was able to correctly classify $93 \%$ of industrial multivarietal extra virgin olive oils on the basis of geographical origin.

Best results in discriminating olive oils on the basis of geographical origins were obtained using MIR spectroscopy in the case of both monovarietal and industrial olive oils.

Figure 3 shows the results obtained applying PCA to MIR spectra of monovarietal olive oils. The score plot (Figure 3a) on PC1 and PC2, which combined explain $98 \%$ of the total variance, shows a very good separation among oils on the basis of geographical origin. In particular, the olive oils from Lombardy and Tuscany were well separated along PC2 $14 \%$ of the total variance) while along PC1 (94\% of the total variance) characterised olive oils from the Calabria region. Examining the 

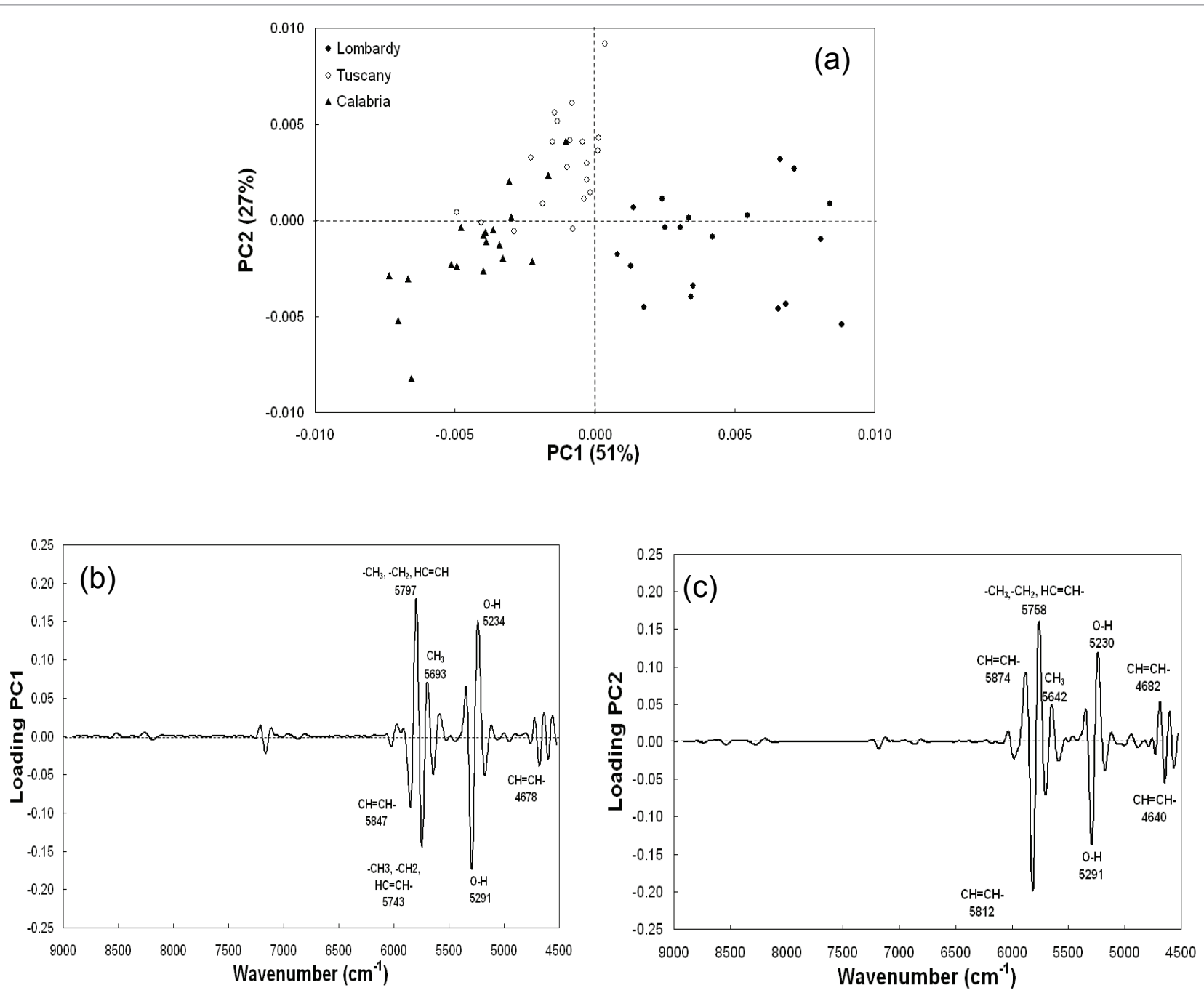

Figure 2. Scores plot defined by PC1 and PC2 (a) and loading plots PC1 (b) and PC2 (c) obtained by applying PCA to the $2^{\text {nd }}$ derivative of industrial extra virgin olive oils spectra.

loading weight of $\mathrm{PC} 1$ and $\mathrm{PC} 2$ [Figure $3(\mathrm{~b})$ and $3(\mathrm{c})$ ], triglyceride functional groups were identified as principal wavenumbers explaining variation among oils belonging to different regions. ${ }^{28-29}$ The major peaks arising from $\mathrm{CH}_{2}$ stretching vibration, asymmetric and symmetric, respectively $\left(2922 \mathrm{~cm}^{-1}\right.$. $\left.2852 \mathrm{~cm}^{-1}\right), \mathrm{C}=0$ stretching vibrations $\left(1743 \mathrm{~cm}^{-1}\right), \mathrm{CH}_{2}$ and $\mathrm{CH}_{3}$ scissoring vibrations $\left(1463 \mathrm{~cm}^{-1}\right.$ and $\left.1377 \mathrm{~cm}^{-1}\right)$ and the coupled $\mathrm{C}-\mathrm{O}$ and $\mathrm{C}-\mathrm{C}$ stretching vibration $\left(1161 \mathrm{~cm}^{-1}\right)$ influenced the separation between Lombardy oils and those from the other two regions.

The ability of FT-IR spectroscopy to discriminate among olive oils of different geographic origin was confirmed by using industrial extra virgin olive oils. A good separation among the regions was obtained by applying PCA to the second derivative of the spectra (results not shown). Also for industrial oils, the absorbance peaks associated with triglyceride functional groups were mainly responsible for sample separation on the basis of geographical region.

Classification techniques were also applied to both monovarietal and industrial extra virgin olive oils MIR spectra in the frequency range $3100-700 \mathrm{~cm}^{-1}$. The best models using LDA and PLS-DA were obtained using second derivative spectral data between $3100 \mathrm{~cm}^{-1}$ and $700 \mathrm{~cm}^{-1}$.

A total of $100 \%$ and $95 \%$ of monovarietal and industrial olive oils, respectively, were correctly classified on the basis of their geographic origin in calibration and in cross-validation by LDA. PLS-DA applied to both monovarietal and industrial MIR spectra allowed a better separation between oils on the basis of geographical origin showing, in prediction, a correct classification rate of $100 \%$.

The spectral data of monovarietal and industrial olive oils were also subjected to analysis by SIMCA and results are shown in Table 2. For each of the three classes, PCA models were built using half of the samples belonging to each category and were tested with the remaining samples. The best models were derived from spectral data in the range $3100-700 \mathrm{~cm}^{-1}$. The SIMCA model applied to monovarietal olive oils was able to identify correctly eight Lombardy olive oils out of eight samples and 10 Tuscany olive oils out of 10 samples using four principal components for both models. The model identified only six Calabria olive oils out of 10 samples, generating four false positive results. However, an overall correct classifica- 

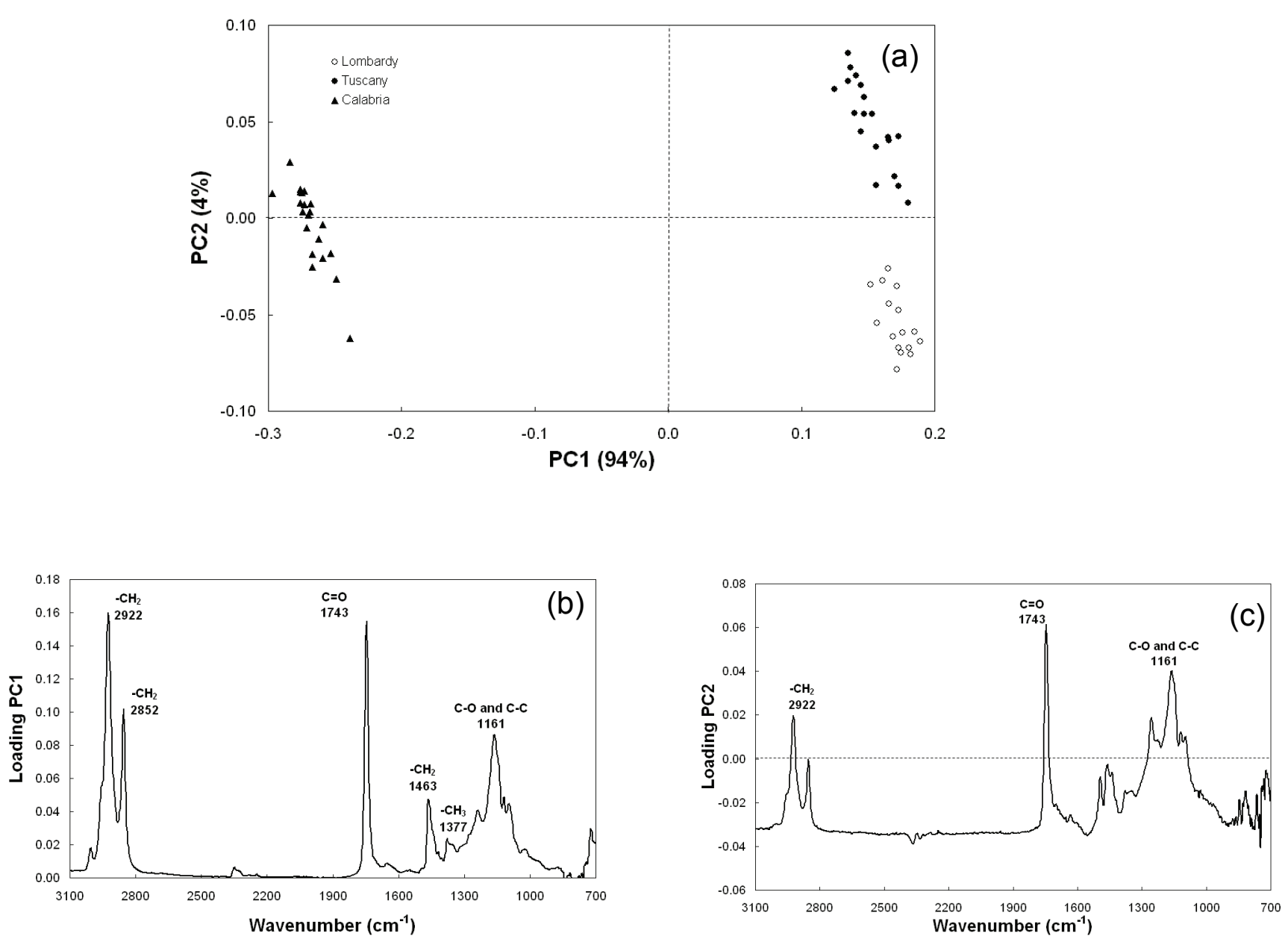

Figure 3. Scores plot defined by PC1 and PC2 (a) and loading plots PC1 (b) and PC2 (c) obtained by applying PCA to the MIR spectra of monovarietal extra virgin olive oils.

tion rate of $86 \%$ was obtained for monovarietal olive oils The SIMCA model applied to industrial olive oils also resulted in the discrimination of oils on the basis of geographical origin, achieving an overall correct classification rate of $96 \%$.

\section{Conclusions}

NIR and MIR spectroscopy combined with chemometric analysis achieved high correct classification rates $(>80 \%)$ of olive oil samples from adjacent geographical areas. Each of the applied classification techniques produced different maximum accuracies. Overall, NIR spectroscopy was able to better classify industrial oils, allowing a correct classification of about $90 \%$ on the basis of geographical origin, while the MIR technique was able to classify both monovarietal and industrial olive oils, allowing a higher correct classification of samples (>95\%). Also the SIMCA method, more conservative than LDA and PLS-DA techniques, was able to classify correctly MIR spectra on the basis of geographical origin. Therefore, these

Table 2. SIMCA classification results of monovarietal and industrial oils using FT-IR spectroscopy (class $1=$ Lombardy oils; class $2=$ Tuscany oils; class $3=$ Calabria oils).

\begin{tabular}{|c|c|c|c|c|c|c|c|c|c|}
\hline \multirow[b]{2}{*}{ Classes } & \multicolumn{5}{|c|}{ Monovarietal oils $(N=60)$} & \multicolumn{4}{|c|}{ Industrial oils ( $N=59)$} \\
\hline & $\mathrm{PCs}$ & $\begin{array}{c}\text { No. } \\
\text { samples } \\
\text { correctly } \\
\text { classified }\end{array}$ & $\begin{array}{c}\text { \% } \\
\text { samples } \\
\text { correctly } \\
\text { classified }\end{array}$ & $\begin{array}{c}\text { False } \\
\text { negative }\end{array}$ & $\begin{array}{c}\text { False } \\
\text { positive }\end{array}$ & $\begin{array}{c}\text { No. } \\
\text { samples } \\
\text { correctly } \\
\text { classified }\end{array}$ & $\begin{array}{c}\text { \% } \\
\text { samples } \\
\text { correctly } \\
\text { classified }\end{array}$ & $\begin{array}{c}\text { False } \\
\text { negative }\end{array}$ & $\begin{array}{c}\text { False } \\
\text { positive }\end{array}$ \\
\hline 1 & 4 & $\begin{array}{c}8 / 8 \\
(100 \%)\end{array}$ & 86 & 0 & 0 & $\begin{array}{c}9 / 9 \\
(100 \%)\end{array}$ & 96 & 0 & 0 \\
\hline 2 & 4 & $\begin{array}{c}10 / 10 \\
(100 \%)\end{array}$ & & 0 & 0 & $\begin{array}{c}10 / 10 \\
(100 \%)\end{array}$ & & 0 & 6 \\
\hline 3 & 7 & $\begin{array}{c}6 / 10 \\
(60 \%)\end{array}$ & & 4 & 0 & $\begin{array}{c}8 / 9 \\
(89 \%)\end{array}$ & & 1 & 5 \\
\hline
\end{tabular}


spectroscopic techniques could be applied for the prediction of geographical origin of olive samples coming from adjacent regions, although more samples, particularly from different harvest years, are needed to improve the accuracy of the classification models developed. This work highlights the advantages of using NIR and MIR spectroscopy instead of chemical analysis.

\section{Acknowledgements}

The authors wish to thank Professor Daniele Bassi (Di.Pro. Ve., University of Milano), Dr Antonio Cimato (Istituto per la Valorizzazione del Legno e delle Specie Arboree, CNR) and Dr Enzo Perri (Istituto Sperimentale per l'Olivicoltura, CRA) for supplying olive and oils of different geographical origin.

\section{References}

1. L. Giordano, "Quality and evaluation of extra virgin olive oil (Italian)", L'Informatore Agrario 15, 97 (2003).

2. Council Regulation (EEC) no. 2081/92, “The protection of geographical indications and designations of origin for agricultural products and foodstuffs", Offic. J. Eur. Union L208, 1 (1992).

3. Commission Regulation (EC) no. 1989/2003, "Amending Regulation (EEC) no. 2568/91 on the characteristics of olive oil and olive-pomace oil and on the relevant methods of analysis", Offic. J. Eur. Union L295, 57 (2003).

4. G. Downey, P. Mclntyre and A.N. Davies, "Detecting and quantifying sunflower oil adulteration in extra virgin olive oils from the eastern Mediterranean by visible and near-infrared spectroscopy", J. Agric. Food Chem. 50, 5520 (2002). doi: $10.1021 /$ jf0257188

5. D. Ozdemir and B. Ozturk, "Near infrared spectroscopic determination of olive oil adulteration with sunflower and corn oil", J. Food Drug Anal. 15, 40 (2007).

6. I.J. Wesley, F. Pacheco and A.E.J. McGill, "Identification of Adulterants in olive oils", JAOCS 73, 515 (1996). doi: 10.1007/BF02523928

7. I.J. Wesley, F. Pacheco and A.E.J. McGill, “Measurement of adulteration of olive oils by near-infrared spectroscopy", JAOCS 72, 289 (1995). doi: 10.1007/BF02541084

8. F.B. Ozen and L.J. Mauer, "Detection of Hazelnut oil adulteration using FT-IR Spectroscopy", J. Agric. Food Chem. 50, 3898 (2002). doi: 10.1021/if0201834

9. V. Baeten, J.A.F. Pierna, P. Dardenne, M. Meurens, D.L. Gargia-Gonzalez and R. Aparicio-Ruiz, “Detection of the presence of hazelnut oil in olive oil by FT-Raman and FT-MIR spectroscopy", J. Agric. Food Chem. 53, 6201 (2005). doi: 10.1021/jf050595n

10. A. Tay, R.K. Singh, S.S. Krishnana and J.P. Gore, "Authentication of olive oil adulterated with vegetable oils using Fourier transform infrared spectroscopy", Lebensmittel Wissenschaft und Technologie 35, 99 (2002). doi: 10.1006/fstl.2001.0864
11. P. Hourant, V. Baeten, M.T. Morales, M. Meurens and R. Aparicio, "Oil and fat classification by selected bands of near-infrared spectroscopy", Appl. Spectrosc. 54, 1168 (2000). doi: 10.1366/0003702001950733

12. H. Yang. J. Irudayaraj and M.M. Paradkar, "Discriminant analysis of edible oils and fats by FTIR, FT-NIR and FT-Raman spectroscopy", Food Chem. 93, 25 (2005). doi: 10.1016/j.foodchem.2004.08.039

13. T. Sato, "Application of principal-component analysis on near-infrared spectroscopic data of vegetable oils for their classification", JAOCS 71, 293 (1994). doi: 10.1007/ $\underline{B F 02638055}$

14. M. Gardiman, P. Tonutti, L. Pizzale, L. Conte and A. Carazzolo, "The effect of hypoxic and $\mathrm{CO}_{2}$-enriched atmospheres on olive ripening and oil quality", Acta Hort. 474, 525 (1999).

15. N. Sinelli, M.S. Cosio, C. Gigliotti and E. Casiraghi, "Preliminary study on application of mid infrared spectroscopy for the evaluation of the virgin olive oil freshness", Anal. Chim. Acta 598, 128 (2007). doi: 10.1016/j. aca.2007.07.024

16. G. Downey, P. Mclntyre and A.N. Davies, "Geographic classification of extra virgin olive oils from the eastern Mediterranean by chemometric analysis of visible and near-infrared spectroscopic data", Appl. Spectrosc. 57, 158 (2003). doi: $\underline{10.1366 / 000370203321535060}$

17. E. Bertran, M. Blanco, J. Coello, H. Iturriaga, S. Maspoch and I. Montoliu, "Near infrared spectrometry and pattern recognition as screening methods for the authentication of virgin olive oils of very close geographical origins", J. Near Infrared Spectrosc. 8, 45 (2000).

18. A. Carazzolo, L. Conte, O. Pavan and P. Tonutti, "Qualità of extra-virgin oil from Veneto olives (Italian)", L'Informatore Agrario 4, 115 (1999).

19. O. Galtier, N. Dupuy, Y. Le Dreau, D. Ollivier, C. Pinatel, J. Kister and J. Artaud, "Geographic origins and compositions of virgin olive oils determinated by chemometric analysis of NIR spectra", Anal. Chim. Acta 595, 136 (2007). doi: 10.1016/j.aca.2007.02.033

20. A. Guadarrama, M.L. Rodriguez-Mendez, C. Sanz, J.L. Rios and J.A. De Saja, "Electronic nose based on conducting polymers for the quality control of the olive oil aroma. Discrimination of quality, variety of olive and geographic origin", Anal. Chim. Acta 432, 283 (2001). doi: 10.1016/S0003-2670(00)01383-0

21. M.S. Cosio, D. Ballabio, S. Benedetti and C. Gigliotti, "Geographical origin and authentication of extra virgin olive oils by an electronic nose in combination with artificial neural networks", Anal. Chim. Acta 567, 202 (2006). doi: $\underline{10.1016 / \text { j.aca.2006.03.035 }}$

22. D. Ballabio, A. Mauri, R. Todeschini and S. Buratti, "Geographical classification of wine and olive oil by means of classification and influence matrix analysis", Anal. Chim. Acta 570, 249 (2006). doi: 10.1016/j. aca.2006.04.029

23. L. Mannina, M. Patumi, N. Proietti, D. Bassi and A.L. Segre, "Geographical characterization of Italian extra 
virgin olive oils using high-field 'H NMR spectroscopy", J. Agric. Food Chem. 49, 2687 (2001). doi: 10.1021/jf001408i

24. M. Uceda, "Factores que influyen en calidad del aceite de oliva (Spanish)", in Proc. Symp. "Expoliva 83", Jean, Spain (1983).

25. Commission Regulation (EEC) no. 2568/91, "The characteristics of olive oil and olive-residue oil and on the relevant methods of analysis", Offic. J. Eur. Commun. L248, 1 (1991).

26. K.R. Beebe, R.J. Pell and M.B. Seasholtz, Chemometrics, a practical guide. John Wiley \& Sons, New York, NY (1998).
27. T. Naes, T. Isaksson, T. Fearn and A.M.C. Davies, A userfriendly guide to multivariate calibration and classification. NIR Publications, Chichester, UK (2000).

28. N.B. Colthup, L.H. Daly and S.E. Wiberly, Introduction to infrared and Raman spectroscopy, Third Edition. Academic Press Inc., New York, NY (1990).

29. J. Workman, "Review of Interpretive Spectroscopy for Raman and Infrared", in Handbook of Organic Compounds, Ed byJ. Workman. Academic Press, London, p. 209 (2001). 